\title{
Effects of nutrition counseling and monitoring on the weight and hemoglobin of patients receiving antiretroviral therapy in Ebonyi State, Southeast Nigeria
}

\author{
This article was published in the following Dove Press journal: \\ HIVIAIDS - Research and Palliative Care \\ 20 May 2014 \\ Number of times this article has been viewed
}

\section{Chihurumnanya Alo \\ Lawrence U Ogbonnaya \\ Benedict N Azuogu}

Department of Community Medicine, Ebonyi State University, Abakaliki, Ebonyi State, Nigeria
Correspondence: Chihurumnanya Alo Department of Community Medicine, Faculty of Clinical Medicine, College of Health Sciences, Ebonyi State University, Abakaliki, PMB 053, Abakiliki, Ebonyi State, Nigeria

Tel +234803677 7800

Email docaloii@yahoo.com
Introduction: The relationship between human immunodeficiency virus (HIV) and malnutrition is easily explained, and the etiology of malnutrition in HIV disease is believed to be multifactorial. It therefore follows that ongoing assessment of nutritional and medical status is crucial to quality nutrition care for every person living with HIV. The aim of this study was to find out the effect of nutritional counseling and monitoring, using personalized dietary prescriptions, on the body mass index (BMI) and hemoglobin of patients who are HIV-infected and also receiving highly active antiretroviral drugs.

Methods: A total of 84 patients were selected using simple random sampling and allocated into intervention and control groups. Nutritional counseling and monitoring was done for the intervention group, while only weight, height, and hemoglobin concentration were monitored for the control group. At the end of 6 months, the differences in mean body mass index (BMI) and hemoglobin concentrations of the intervention and control groups were compared using the Student's $t$-test. Statistical level of significance was put at $P<0.05$.

Results: Among respondents, 30.96\% were males and $69.04 \%$ were females, and the mean age of the intervention group was 33.8 years and was 35.3 in the control group. After 6 months of study, the difference in the mean BMI among the males of both groups $\left(24.9 \mathrm{~kg} / \mathrm{m}^{2}\right.$ [intervention] and $24.3 \mathrm{~kg} / \mathrm{m}^{2}$ [control]) was not significant $(P=0.53)$ but was significant among the females (24.9 kg/m $\mathrm{m}^{2}$ [intervention group] versus $21.8 \mathrm{~kg} / \mathrm{m}^{2}$ [control group]) $(P=0.0005)$. The difference in mean hemoglobin concentration between the intervention and control groups for both males and females were statistically significant $(12.2 \mathrm{mg} / \mathrm{dL}$ for males in the intervention group and $11.0 \mathrm{mg} / \mathrm{dL}$ for males in the control group $[P=0.005] ; 11.9 \mathrm{mg} / \mathrm{dL}$ for females in the intervention group and $11.0 \mathrm{mg} / \mathrm{dL}$ for females in the control group [ $P=0.0108]$ ).

Conclusion: Nutrition intervention is important in the management of people living with HIV/ acquired immunodeficiency disease (AIDS) while on antiretroviral therapy. This can be achieved through nutritional counseling and monitoring.

Keywords: AIDS, hemoglobin, weight, HIV, BMI, counseling, intervention

\section{Introduction}

In the past, when the human immunodeficiency virus (HIV) was discovered as the virus that causes acquired immunodeficiency syndrome (AIDS), the primary goal of nutrition counseling for people living with HIV involved specific strategies for managing weight loss and wasting. ${ }^{1}$ By the mid-1990s when highly active antiretroviral therapy (HAART) was introduced, changes in the management of those living with 
the virus meant that patients could now live healthier, longer, and more productive lives. ${ }^{1}$ This makes adequate nutrition in persons infected with HIV very important. The relationship between HIV and malnutrition is easily explained, and the etiology of malnutrition in HIV disease has been shown to be multifactorial. The implicated factors include altered nutrient intake, malabsorption, or metabolic changes. Inadequate food intake may also occur as a result of anorexia, dysgeusia, dysphagia, depression, or lack of access to adequate foods. ${ }^{2}$ It therefore follows that ongoing assessment of nutritional and medical status is crucial to quality nutrition care for every person living with HIV. ${ }^{1}$ Usually included in the assessment and monitoring is a complete baseline nutrition assessment. This should be done for each patient. Both baseline and ongoing assessment examine changes in body composition, clinical, and biochemical parameters, dietary intake, as well as psychosocial issues. Anthropometric measurements, including measures of body weight, body mass index (BMI), and subcutaneous fat stores, can help the nutrition professional identify and track changes in body composition. ${ }^{3}$ Previous study points to low energy intake combined with increased energy demands, due to HIV infection and related infections, as the major driving forces behind HIV-related weight loss and wasting. Nutrition experts recommend that energy needs be increased by $10 \%$ over accepted levels for otherwise healthy people. This is based on the increased resting energy expenditure that has been observed in the study of HIV-infected adults. ${ }^{4}$ During the course of HIV treatment, the patient may experience muscle loss, subcutaneous fat loss, or fat hypertrophy, which may or may not be reflected in the patient's total body weight. For this reason, it is vital to assess body composition on a regular basis. Regular assessment of body weight and body composition can help in the early detection and treatment of morphologic changes, such as the loss, accumulation, and/or altered distribution of fat as well as AIDS wasting syndrome. ${ }^{1}$

Hematologic abnormalities, including anemia, are common manifestations of HIV infection and AIDS. Anemia may result from the indirect effects of HIV infection, including adverse reactions to medications, opportunistic infections, neoplasms, or nutritional abnormalities stemming from anorexia, malabsorption, or metabolic disorders. The resultant anemia can impact daily quality of life by inducing such symptoms as loss of stamina, rapid heart rate, and shortness of breath. Anemia has been shown to be a risk factor for early death in patients with AIDS. ${ }^{5}$ Previous study found that nutritional supplementation taken concurrently with antiretroviral therapy (ART) improved hemoglobin, red blood cell, and white blood cell count, and suggested that the best way to prevent anemia is by eating a wide variety of nutritious food. ${ }^{6}$

Nutrition intervention includes both food-based approaches and micronutrient supplementation. Researchers have employed both in the past. Both approaches have their benefits and challenges. ${ }^{7}$

The aim of this study was to find out the effect of nutritional counseling and monitoring, using individualized dietary prescriptions, on the BMI and hemoglobin of patients who are HIV infected and also receiving HAART in our setting.

\section{Methods}

This study was carried out at Ebonyi State University Teaching Hospital in Abakaliki, Ebonyi State, Southeast Nigeria. The hospital offers HIV care and services among other primary, secondary, and tertiary care services for other aspects of health care. At the time of this study, the HIV clinic had about 750 patients in its enrolment. The study was a 6-month, quasi-experimental study of HIV infected patients who were receiving treatment with HAART and who also accessed care from the HIV clinic. The sample size was calculated using the following formula

$$
\mathrm{n}=\frac{(\mathrm{A}+\mathrm{B})^{2} \times\left(\left[\mathrm{p}_{1} \times\left\{1-\mathrm{p}_{1}\right\}\right]+\left[\mathrm{p}_{2} \times\left\{1-\mathrm{p}_{2}\right\}\right]\right)}{\left(\mathrm{p}_{1}-\mathrm{p}_{2}\right)^{2}},
$$

where $\mathrm{n}=$ the sample size required in each group; $\mathrm{A}=1.96$, the level of significance; $\mathrm{B}=0.84$, desired power at $80 \%$; $p_{1}=0.75$, the estimated proportion of HIV patients that would receive a nutrition intervention; $\mathrm{p}_{2}=0.40$, the estimated proportion of HIV patients that would not receive a nutrition intervention; and $\mathrm{p}_{1}-\mathrm{p}_{2}=0.35$, the level of change or difference from nutritional intervention chosen to be of clinical importance.

The calculated sample size was 84 participants. The participants were selected using a simple random sampling technique and were then randomized into intervention and control groups made up of 42 participants in each group. These patients were all receiving HAART, including zidovudine, lamivudine, nevirapine, and efavirenz. None of the patients were on a protease inhibitor. The eligibility criteria included: patients who gave consent to participate, patients who were residents within Abakaliki town, and patients without opportunistic infections at the beginning of the study. Patients who were pregnant at the time of study or who were likely to become pregnant during the course 
of study were excluded. The intervention group received nutritional counseling. This included dietary counseling and individualized food prescriptions based on locally available food and counseling on food hygiene. The individualized prescription included assessment of foods easily available and affordable by individual patients, and assessment of patients' daily energy requirement. The daily energy requirement was calculated using the formula

$$
\mathrm{TER}=\mathrm{RMR}+\mathrm{TEF}+\text { physical activity, }
$$

where, TER was the thermic effect of food, TER was total energy requirement and RMR was the resting metabolic rate. Calculating this daily energy requirement for each patient ensured that the patients' energy intake did not go below daily energy expenditure. Also, the nutritionist ensured that the food prescriptions contained food from all food classes.

Both groups had anthropometric measurements, such as weight, height, and BMI, and hemoglobin concentration measured at baseline and then monthly for 6 months. Only the intervention group received nutrition counseling on a monthly basis, during their scheduled monthly clinic visits. At the end of 6 months, the differences in the mean BMI between the intervention group and control group were calculated. The difference in mean hemoglobin concentration between the intervention and control groups was also calculated. This was done using the Student's $t$-test. The tools used for the measurements included a stadiometer/body weight scale (model ZT-120; Sino-Resource International Trade Co, Ltd, Tianjin, People's Republic of China). This was used to measure weight and height. Venous blood, drawn in the morning in the laboratory during each clinic visit, was used for the hemoglobin level. Hemoglobin estimation was done using the HemoCue ${ }^{\mathrm{TM}} \mathrm{Hb}$ 201DM Analyzer (Thermo Fisher Scientific Inc., Waltham, MA, USA) in the laboratory. Dietary counseling and food prescriptions were obtained from the Nutrition and Dietetics department of the hospital. The nutrition counseling was done by the nutritionist attached to the HIV clinic. A semistructured questionnaire was used to collect information from the patients. The information included demographic data, date of enrollment into ART, height, weight, and 24-hour food recall. The questionnaire was administered at every clinic visit, and information, such as weight, food recall, and hemoglobin, was updated. All patients selected for this study completed the study. Data were analyzed using SPSS Version 16 (SPSS, Inc., Cary, NC, USA). Ethical clearance was duly obtained from the Ethics and Research committee of the hospital.

\section{Results}

Table 1 shows the age, sex distribution, and the mean age of the respondents. Males (30.96\%) were 26 years, while females $(69.04 \%)$ were 58 years. The mean age of the participants was 33.8 years in the intervention group and 35.3 years in the control group. Most of the participants were within the age group of 25-29 years (25\%), followed by participants within the age group of 35-39 years (23.8\%), while fewest participants were in the age group 60-64 years $(2.3 \%)$. There was also no significant difference in the mean age of both intervention and control group, thus making them comparable.

We compared the mean BMI of both the intervention and control groups, segregated by sex, from baseline to 6 months after intervention (Table 2). The results showed that at baseline, among the males, the mean BMI was 23.1 $\mathrm{kg} / \mathrm{m}^{2}$ in the intervention group and $23.3 \mathrm{~kg} / \mathrm{m}^{2}$ in the control group. This difference in mean BMI at baseline was not significant $(t=0.19, P=0.8514)$. Among the female participants, at baseline, the mean BMI within the intervention group was $21.9 \mathrm{~kg} / \mathrm{m}^{2}$ and was $20.3 \mathrm{~kg} / \mathrm{m}^{2}$ in the control group. The difference in their mean was also not significant $(t=1.10, P=0.2819)$. After 6 months of nutritional counseling and monitoring, the mean BMI in males and females, in both intervention and control groups, were also compared. Among the males, the mean BMI was $24.9 \mathrm{~kg} / \mathrm{m}^{2}$ (intervention group) and $24.3 \mathrm{~kg} / \mathrm{m}^{2}$ (control group). The difference in mean was not significant ( $t=0.62, P=0.5379)$. The mean

Table I Age and sex distribution of intervention and control respondents

\begin{tabular}{lllll}
\hline Sex & $\begin{array}{l}\text { Intervention } \\
\text { group } \\
\mathbf{n}(\%)\end{array}$ & $\begin{array}{l}\text { Control } \\
\text { group } \\
\mathbf{n}(\%)\end{array}$ & $\begin{array}{l}\text { Total } \\
\mathbf{n}(\%)\end{array}$ & $\begin{array}{l}\text { Statistical } \\
\text { indices }\end{array}$ \\
\hline Males & I5 (35.7) & II (26.2) & $26(30.96)$ & \\
Females & $27(64.3)$ & 3 I (73.8) & $58(69.04)$ & \\
Total & 42 & 42 & 84 & \\
Age group (yrs) & & & \\
$20-24$ & $4(9.52)$ & $3(7.14)$ & $7(8.33)$ & \\
$25-29$ & $10(23.8)$ & II (26.19) & $21(25)$ & \\
$30-34$ & $9(21.46)$ & $9(21.45)$ & $18(21.4)$ & \\
$35-39$ & $10(23.8)$ & $10(23.8)$ & $20(23.8)$ & \\
$40-44$ & $6(14.28)$ & $2(4.76)$ & $8(9.52)$ & \\
$45-49$ & $2(4.76)$ & $1(2.38)$ & $3(3.57)$ & \\
$50-54$ & $0(0)$ & $2(4.76)$ & $2(2.38)$ & \\
$55-59$ & $0(0)$ & $3(7.14)$ & $3(3.57)$ & \\
$60-64$ & I (2.38) & I (2.38) & $2(2.38)$ & \\
Total & 42 & 42 & 84 & $t=0.76 \mid$ \\
Mean & $33.8(7.7)$ & $35.3(10.2)$ & & $d f=82$ \\
age (SD) & & & & $P>0.05$ \\
\hline
\end{tabular}

Abbreviations: $d f$, degrees of freedom; SD, standard deviation; yrs, years. 
Table 2 Mean and standard deviation of the body mass index of enrolled patients, segregated by sex

\begin{tabular}{|c|c|c|c|c|c|c|}
\hline \multirow[t]{2}{*}{ Month } & \multicolumn{3}{|l|}{ Males } & \multicolumn{3}{|l|}{ Females } \\
\hline & $\begin{array}{l}\text { Intervention } \\
\text { mean (SD) } \\
\mathrm{n}=\mathrm{I5}\end{array}$ & $\begin{array}{l}\text { Control } \\
\text { mean (SD) } \\
\mathrm{n}=\mathrm{I} \mathrm{I}\end{array}$ & $\begin{array}{l}\text { Statistical } \\
\text { indices }\end{array}$ & $\begin{array}{l}\text { Intervention } \\
\text { mean (SD) } \\
\mathrm{n}=\mathbf{2 7}\end{array}$ & $\begin{array}{l}\text { Control } \\
\text { mean (SD) } \\
n=31\end{array}$ & $\begin{array}{l}\text { Statistical } \\
\text { indices }\end{array}$ \\
\hline 0 & $23.1(3.0)$ & $23.3(2.1)$ & $\begin{array}{l}t=0.19 \\
d f=24 \\
P=0.85 I 4\end{array}$ & 21.9 (3.9) & $20.3(3.3)$ & $\begin{array}{l}t=1.10 \\
d f=56 \\
P=0.2819\end{array}$ \\
\hline 1 & $23.8(3.1)$ & $23.1(2.2)$ & $\begin{array}{l}t=0.64 \\
d f=24 \\
P=0.529\end{array}$ & $22.5(3.8)$ & $20.7(3.1)$ & $\begin{array}{l}t=1.99 \\
d f=56 \\
P=0.0519\end{array}$ \\
\hline 2 & $24.0(3.0)$ & $23.7(2.2)$ & $\begin{array}{l}t=0.28 \\
d f=24 \\
P=0.7842\end{array}$ & 23.1 (3.7) & $20.7(3.2)$ & $\begin{array}{l}t=2.56 \\
d f=56 \\
P=0.0104\end{array}$ \\
\hline 3 & $24.5(3.3)$ & $23.8(2.3)$ & $\begin{array}{l}t=0.58 \\
d f=24 \\
P=0.5657\end{array}$ & $23.8(3.6)$ & $21.3(2.9)$ & $\begin{array}{l}t=2.93 \\
d f=56 \\
P=0.0049\end{array}$ \\
\hline 4 & $25.0(3.3)$ & 24.I (2.6) & $\begin{array}{l}t=0.75 \\
d f=24 \\
P=0.46 I 2\end{array}$ & $24.4(3.4)$ & $20.7(3.4)$ & $\begin{array}{l}t=4.13 \\
d f=56 \\
P=0.0001\end{array}$ \\
\hline 5 & $24.4(2.4)$ & $24.4(2.6)$ & $\begin{array}{l}t=0.00 \\
d f=24 \\
P=1.0000\end{array}$ & $24.7(3.2)$ & $21.3(3.2)$ & $\begin{array}{l}t=4.04 \\
d f=56 \\
P=0.000 I\end{array}$ \\
\hline 6 & $24.9(2.5)$ & $24.3(2.3)$ & $\begin{array}{l}t=0.62 \\
d f=24 \\
P=0.5379\end{array}$ & $24.9(3.0)$ & $21.8(3.4)$ & $\begin{array}{l}t=3.66 \\
d f=56 \\
P=0.0005\end{array}$ \\
\hline
\end{tabular}

Abbreviations: $d f$, degrees of freedom; $S D$, standard deviation.

BMI for the females was $24.9 \mathrm{~kg} / \mathrm{m}^{2}$ (intervention group) and $21.8 \mathrm{~kg} / \mathrm{m}^{2}$ (control group). This difference in mean was significant ( $t=3.66, P=0.0005)$.

We also combined both male and female results among the intervention and control groups for both BMI and hemoglobin. The results showed that at baseline, the difference in mean of BMI between the intervention group $\left(22.3 \mathrm{~kg} / \mathrm{m}^{2}\right)$ and the control group $\left(21.15 \mathrm{~kg} / \mathrm{m}^{2}\right)$ was not significant ( $t=1.53, P=0.1308$ ). In the course of the study, both groups showed an increase in mean BMI (Table 2). However after 6 months of intervention, the difference in mean between both intervention group $\left(24.9 \mathrm{~kg} / \mathrm{m}^{2}\right)$ and control group $\left(22.50 \mathrm{~kg} / \mathrm{m}^{2}\right)$ was significant $(t=3.59, P=0.0005)$ (Table 3). The results for hemoglobin showed that at baseline, the difference in mean hemoglobin between the intervention group $(10.4 \mathrm{mg} / \mathrm{dL})$ and control $(10.3 \mathrm{mg} / \mathrm{dL})$ group was not significant $(t=0.28, P=0.7827)$. After 6 months of intervention, the mean hemoglobin concentration between the intervention group $(12.1 \mathrm{mg} / \mathrm{dL})$ and control $(11.2 \mathrm{mg} / \mathrm{dL})$ was also compared. The difference in means was significant ( $t=3.28, P=0.0015)$.

Table 4 shows the comparison of the mean hemoglobin concentration between the intervention and control groups from baseline to 6 months, segregated by sex. At baseline among the males, the difference in the mean hemoglobin concentration of the intervention group $(10.9 \mathrm{mg} / \mathrm{dL})$ and control $(10.6 \mathrm{mg} / \mathrm{dL})$ was not significant $(t=0.61, P=0.55)$. There was also no difference in the mean hemoglobin concentration among female subjects $(10.1 \mathrm{mg} / \mathrm{dL})$ and controls $(10.1 \mathrm{mg} / \mathrm{dL})(t=0.00, P=1.00)$. After 6 months of intervention, the difference between the mean hemoglobin concentration of the males and females, in both the intervention and control groups, was significant. Among the males, the means were $12.2 \mathrm{mg} / \mathrm{dL}$ for the intervention group and $11.0 \mathrm{mg} / \mathrm{dL}$ for the control group $(t=3.02, P=0.0058)$, while among the

Table 3 Mean, standard deviation of BMI and hemoglobin of the intervention and control groups, compared at month zero and after 6 months

\begin{tabular}{|c|c|c|c|}
\hline \multirow[t]{3}{*}{ Month } & Intervention & Control & \multirow{3}{*}{$\begin{array}{l}\text { Statistical } \\
\text { indices }\end{array}$} \\
\hline & \multicolumn{2}{|l|}{ BMI } & \\
\hline & Mean (SD) & Mean (SD) & \\
\hline 0 & $23.6(3.6)$ & 21.15 & $t=1.53, P=0.1308$ \\
\hline \multirow[t]{3}{*}{6} & $24.9(2.8)$ & $22.50(3.3)$ & $t=3.59, P=0.0005$ \\
\hline & \multicolumn{2}{|l|}{ Hemoglobin } & \\
\hline & Mean (SD) & Mean (SD) & \\
\hline 0 & $10.4(1.8)$ & $10.3(1.5)$ & $t=0.28, P=0.7827$ \\
\hline 6 & I2.I (I.3) & II.2(I.I) & $t=3.28, P=0.0015$ \\
\hline
\end{tabular}

Abbreviations: BMI, body mass index; SD, standard deviation. 
Table 4 The mean and standard deviation of hemoglobin concentration of enrollees throughout the study

\begin{tabular}{|c|c|c|c|c|c|c|}
\hline \multirow[t]{2}{*}{ Month } & \multicolumn{3}{|l|}{ Males } & \multicolumn{3}{|l|}{ Females } \\
\hline & $\begin{array}{l}\text { Intervention } \\
\text { mean (SD) } \\
n=15\end{array}$ & $\begin{array}{l}\text { Control } \\
\text { mean (SD) } \\
\mathrm{n}=\mathrm{I} \mid\end{array}$ & $\begin{array}{l}\text { Statistical } \\
\text { indices }\end{array}$ & $\begin{array}{l}\text { Intervention } \\
\text { mean (SD) } \\
n=27\end{array}$ & $\begin{array}{l}\text { Control } \\
\text { mean (SD) } \\
n=31\end{array}$ & $\begin{array}{l}\text { Statistical } \\
\text { indices }\end{array}$ \\
\hline 0 & $10.9(1.4)$ & $10.6(1.0)$ & $\begin{array}{l}t=0.6 \mathrm{I} \\
d f=24 \\
P=0.5508\end{array}$ & $10.1(1.9)$ & $10.1(1.4)$ & $\begin{array}{l}t=0.00 \\
d f=56 \\
P=1.000\end{array}$ \\
\hline I & II.2(I.3) & $10(1.5)$ & $\begin{array}{l}t=2.18 \\
d f=24 \\
P=0.0393\end{array}$ & $10.6(1.8)$ & I0.I (I.3) & $\begin{array}{l}t=1.22 \\
d f=56 \\
P=0.2262\end{array}$ \\
\hline 2 & II.2 (I.I) & $10.3(1.4)$ & $\begin{array}{l}t=1.84 \\
d f=24 \\
P=0.0785\end{array}$ & $10.9(1.9)$ & $10.3(1.3)$ & $\begin{array}{l}t=1.42 \\
d f=56 \\
P=0.1615\end{array}$ \\
\hline 3 & II .5 (0.9) & $10.4(1.3)$ & $\begin{array}{l}t=2.55 \\
d f=24 \\
P=0.0173\end{array}$ & II.5 (0.9) & $10.4(1.3)$ & $\begin{array}{l}t=3.69 \\
d f=56 \\
P=0.0005\end{array}$ \\
\hline 4 & II.7 (I.0) & $10.5(1.4)$ & $\begin{array}{l}t=2.55 \\
d f=24 \\
P=0.0173\end{array}$ & II.3 (I.7) & I0.5 (I.4) & $\begin{array}{l}t=0.00 \\
d f=56 \\
P=1.000\end{array}$ \\
\hline 5 & $11.9(1.1)$ & $10.8(1.3)$ & $\begin{array}{l}t=2.33 \\
d f=24 \\
P=0.0283\end{array}$ & II.6 (1.6) & $10.7(1.3)$ & $\begin{array}{l}t=2.36 \\
d f=56 \\
P=0.0216\end{array}$ \\
\hline 6 & $12.2(1.0)$ & II (I.0) & $\begin{array}{l}t=3.02 \\
d f=24 \\
P=0.0058\end{array}$ & 11.9 (1.4) & II.4 (I.2) & $\begin{array}{l}t=2.64 \\
d f=56 \\
P=0.0108\end{array}$ \\
\hline
\end{tabular}

Abbreviations: $d f$, degrees of freedom; SD, standard deviation.

females, the mean hemoglobin was $11.9 \mathrm{mg} / \mathrm{dL}$ in the intervention group and $11.0 \mathrm{mg} / \mathrm{dL}$ in the control group $(t=2.64$, $P=0.0108)$.

\section{Discussion}

In our study, the BMIs of males and females in the intervention group both showed an increase. After 6 months, the BMI was $24.9 \mathrm{~kg} / \mathrm{m}^{2}$ for both males and females. The World Health Organization (WHO) suggests the following classification of BMI values: ${ }^{8}<18.5 \mathrm{~kg} / \mathrm{m}^{2}$ (thinness); $18.5-24.9 \mathrm{~kg} / \mathrm{m}^{2}$ (eutrophy); 25-29.9 kg/m² (overweight); 30-39.9 kg/m² (obesity); and $>40 \mathrm{~kg} / \mathrm{m}^{2}$ (morbid obesity). In our study, the mean BMI reflects a eutrophic population. This suggests that nutrition intervention can help people living with HIV/AIDS (PLWHA) to maintain adequate weight during the course of infection and treatment with HAART. ${ }^{9}$ One study has shown that the prevalence of thinness among HIV-infected people in the era of HAART is about $8.8 \% .^{9}$ This provides an understanding of why weight loss and malnutrition continue to be common problems among HIV-infected patients in developing communities, even in the era of ART. ${ }^{10,11}$ A previous study also showed that low BMI at ART initiation was an independent predictor of mortality. ${ }^{12}$ This study also showed that those with a BMI between 16.0 and $16.9 \mathrm{~kg} / \mathrm{m}^{2}$ had a 2.1-fold increased risk of early mortality (95\% confidence interval [CI]: 1.7-2.5), and those with a BMI of $16.0 \mathrm{~kg} /$ $\mathrm{m}^{2}$ had a 2.3 -fold increased risk (95\% CI: 2.0-2.7). ${ }^{12} \mathrm{BMI}$, therefore, is a useful tool to detect chronic energy deficiency and has also been proposed as an indicator of HIV progression, in developing countries. ${ }^{13,14}$

In our study, nutrition intervention had a significant effect on the BMI of females in intervention group when compared with that in females in the control group. This was not so for the males. The effect was not significant when the difference in mean BMI of males in the intervention group was compared with the difference in the control group. This pattern could not be explained by our study, but when the results for both males and females were aggregated, the difference between the mean BMI of the intervention group and control group was found to be significant. One explanation could be that going to the market to buy food and cooking are considered female activities, possibly helping the females adhere to the nutrition counseling and hence, having a significant change in nutritional status. The results of another study also showed the positive effect of nutrition intervention on the maintenance of body weight in HIV-positive persons and support the principle of including nutrition intervention as a first line of defense in the care of HIV-infected patients. ${ }^{2}$ The authors obtained a 
positive outcome among the intervention group despite its concentration of severely compromised patients, which further supports the importance of nutrition intervention. ${ }^{2}$

We also understand that obesity is becoming more common among PLWHA after the introduction of HAART. A number of laboratory studies have suggested the possibility of interaction between ART medications and several enzymes or hormones associated with lipid metabolism, mitochondrial toxicity of nucleoside reverse transcriptase inhibitors, insulin resistance associated with protease inhibitors, and cytokine dysregulation. Even with this "multiple pathway" hypothesis, the role of HAART remains unclear in the pathophysiology of lipodystrophy syndrome. ${ }^{15}$ All our patients were receiving zidovudine and lamivudine, both of which are nucleoside reverse transcriptase inhibitors. This could also have contributed to the eutrophic BMI of intervention and control groups.

The insignificant difference in the mean BMI of intervention group males and control group males in this study does not preclude offering nutritional counseling to PLWHA. This was also revealed in a study that assessed the relationship of energy intake to weight changes. The researchers concluded that the relationship was complex. Their data suggest that an increase in energy intake is not likely to increase weight, but they nevertheless recommended that all patients with HIVrelated weight loss receive nutrition counseling so that energy intake is optimized. ${ }^{16}$ Consequently, nutrition counseling can improve health outcomes and should be an integral part of HIV care at any stage of the disease - from helping newly infected people to stay healthy and assisting people taking ART to manage their therapy, to allowing people with endstage AIDS to die with dignity. ${ }^{17}$

A relationship between nutritional intervention and hemoglobin concentration was observed in our study. The difference between the mean hemoglobin concentration of the group that received nutrition intervention and that of the control group was statistically significant. This suggests that the development of anemia in HIV patients is an important factor that should be considered in their management. Hemoglobin is the iron-containing oxygen transport metalloprotein in the blood. Reduction in hemoglobin concentration leads to depletion of iron stores..$^{18}$ Iron deficiency ranges from iron depletion, which causes little physiological damage, to iron deficiency anemia, which can affect the function of numerous organ systems. Iron depletion also causes the amount of stored iron to be reduced. Consequently, a person with no stored iron has no reserve should the body enter a state where more iron is required than is being absorbed from the diet. ${ }^{18}$ Anemia is associated with more rapid progression to AIDS, increased risk of death, and fatigue, as well as a greater need for transfusions. ${ }^{19}$ A study done in Nigeria revealed that anemia was a major problem of people living with HIV/ AIDS and that those who received nutritional counseling and micronutrient supplementation had an increase in packed cell volume levels, while their controls had reductions..$^{20}$ In that study, about 49 (35.5\%) of the controls were anemic, and the authors inferred that nutritional counseling and micronutrient supplementation were effective in improving the packed cell volume of HIV patients. Elsewhere, researchers studied the predictors of mortality in HIV-infected patients starting ART. ${ }^{21}$ They showed that anemia was a strong predictor of mortality and that severely anemic patients had nearly a 15-fold higher risk of dying during the first year on HAART compared with those with normal hemoglobin level. ${ }^{21}$

Our findings in this study have clinical implications. One is that monitoring weight and hemoglobin in PLWHA can be of benefit to their nutritional needs. Secondly, nutritional counseling can provide PLWHA with information on how to achieve a balanced diet from locally available foods. Weight and hemoglobin monitoring are simple to carry out. Therefore these could be applied at primary- and secondarylevel clinics.

An important strength of our study is that Abakaliki is an agrarian community. Foods that can provide the needed nutrients are readily available and affordable. A second strength was that all patients involved in the study adhered to their clinic visits and appointments because our clinic has a strong treatment support service. Also our patients were randomized, hence many factors that could have affected our findings were randomly distributed between the intervention and control groups.

A major weakness in this study is that it did not account for the effect of ART on fat metabolism, which can affect weight gain.

\section{Conclusion}

Our study has shown that nutrition intervention is important in the management of PLWHA while on ART. This can be achieved through nutritional counseling and monitoring of PLWHA in resource-constrained practice areas.

\section{Disclosure}

The authors report no conflicts of interest in this work.

\section{References}

1. Hendrick KM, Dong KR, Gerrior JL. Nutrition Management of HIV and AIDS. Chicago, IL: American Dietetics Association; 2009. 
2. McKinley MJ, Goodman-Block J, Lesser ML, Salbe AD. Improved body weight status as a result of nutrition intervention in adult, HIV-positive outpatients. J Am Diet Assoc. 1994;94(9):1014-1017.

3. Shevitz A, Wanke CA, Falutz J, Kotler DP. Clinical perspectives on HIV-associated lipodystrophy syndrome; an update. AIDS. 2001;15(15): 1017-1930.

4. World Health Organization. Nutrient Requirements for People Living With HIV/AIDS; Report of a Technical Consultation. Geneva: World Health Organization; 2003.

5. Mocroft A, Kirk O, Barton SE, et al; EuroSIDA Study Group. Anaemia is an independent predictive marker for clinical prognosis in HIV-infected patients from across Europe. AIDS. 1999;13(8):943-950.

6. Houtzager LM. Nutrition in HIV: a review. J Postgrad Med. 2009;11(1): $62-75$.

7. Rawat R, McCoy SI, Kadiyala S. Poor diet quality is associated with low CD4 count and anemia and predicts mortality among antiretroviral therapy - naive HIV-positive adults in Uganda. J Acquir Immune Defic Syndr. 2013;62(2):246-253.

8. World Health Organization. Diet, nutrition and the prevention of chronic disease. Geneva: World Health Organization; 1990. (WHO Technical Report Series, 797).

9. Mariz Cde A, Albuquerque Mde F, Ximenes RA, et al. Body mass index in individuals with HIV infection and factors associated with thinness and overweight/obesity. Cad. Saúde Pública [serial on the Internet]. Oct 2011 [cited September 21, 2013];27(10):1997-2008. Available from: http://www.ncbi.nlm.nih.gov/pubmed/22031204. Accessed March 19, 2014.

10. Jerene D, Endale A, Hailu Y, Lindtjørn B. Predictors of early death in a cohort of Ethiopian patients treated with HAART. BMC Infect Dis. 2006;6:136-143.

11. Koethe JR, Heimburger DC. Nutritional aspects of HIV-associated wasting in sub-Saharan Africa. Am J Clin Nutr. 2010;91(4):1138S-1142S.

12. Liu E, Spiegelman D, Semu H, et al. Nutritional status and mortality among HIV-infected patients receiving antiretroviral therapy in Tanzania. J Infect Dis. 2011;204(2):282-290.
13. Madec Y, Szumilin E, Genevier C, et al. Weight gain at 3 months of antiretroviral therapy is strongly associated with survival: evidence from two developing countries. AIDS. 2009;23(7):853-861.

14. Sicotte M, Ledoux M, Zunzunegui MV, Ag Aboubacrine S, Nguyen VK; ATARAO Group. Reliability of anthropometric measures in a longitudinal cohort of patients initiating ART in West Africa. BMC Med Res Methodol. 2010;10:102.

15. Lichtenstein KA, Delaney KM, Armon C, et al; HIV Outpatient Study Investigators. Incidence and risk factor for lipoatrophy (abnormal fat loss) in ambulatory HIV-1-infected patients. J Acquir Immune Defic Syndr. 2003;32(1):48-56.

16. Mwamburi DM, Wilson IB, Jacobson DL, et al. Understanding the role of HIV load in determining weight change in the era of highly active antiretroviral therapy. Clin Infect Dis. 2005;40(1):167-173.

17. American Dietetic Association. Position of the American Dietetic Association and Dieticians of Canada: Nutrition intervention in the care of persons with human immunodeficiency virus infection. J Am Diet Assoc. 2004;104:1425-1441.

18. Woods MN, Spiegelman D, Knox TA, et al. Nutrient intake and body weight in a large HIV cohort that includes women and minorities. $J$ Am Diet Assoc. 2002;102(2):203-211.

19. Kaiser JD, Campa AM, Ondercin JP, Leoung GS, Pless RF, Baum MK. Micronutrient supplementation increases CD4 count in HIV-infected individuals on highly active antiretroviral therapy: a prospective, double-blinded, placebo-controlled trial. J Acquir Immune Defic Syndr. 2006;42(5):523-528.

20. Opara DC, Umoh IB, John M. Effects of nutritional counseling and micronutrient supplementation on some biochemical parameters on persons living with HIV/AIDS in Uyo, Nigeria. Pakistan Journal of Nutrition. 2007;6(3):220-227.

21. Johannessen A, Naman E, Ngowi BJ, et al. Predictors of mortality in HIV-infected patients starting antiretroviral therapy in a rural hospital in Tanzania. BMC Infect Dis. 2008;8:52.
HIV/AIDS - Research and Palliative Care

\section{Publish your work in this journal}

HIV/AIDS - Research and Palliative Care is an international, peerreviewed open-access journal focusing on advances in research in HIV, its clinical progression and management options including antivira treatment, palliative care and public healthcare policies to control viral spread. The journal welcomes original research, basic science,

\section{Dovepress}

clinical \& epidemiological studies, reviews \& evaluations, expert opinion \& commentary, case reports \& extended reports. The manuscript management system is completely online and includes a very quick and fair peer-review system. Visit http://www.dovepress.com/ testimonials.php to read real quotes from published authors. 